\title{
EINLEITUNG DES HERAUSGEBERS
}

\section{NOTWENDIGKEIT EINER NEUAUSGABE}

Die Notwendigkeit einer kritischen Neuausgabe der Glaubenslehre Schleiermachers ist nicht zu bestreiten. Sie ist nicht nur deshalb erforderlich, weil dieses klassische Werk der neuprotestantischen Dogmatik seit längerer Zeit nicht mehr im regulären Buchhandel zu erhalten ist, sondern weil diese theologische Hauptschrift Schleiermachers bisher als Ganzes überhaupt noch nicht textkritisch bearbeitet worden ist. Nur die einleitenden Paragraphen hat vor Jahren Carl Stange in einer kritischen Ausgabe erscheinen lassen. Sonstige bekanntere Schriften Schleiermachers, z. B. seine Reden, die Monologen und die "Kurze Darstellung des theologischen Studiums" sind längst in einer neuen kritischen Bearbeitung erschienen. Die Glaubenslehre aber hat außer den beiden Auflagen, die Schleiermacher selbst besorgte (1. Auflage 1821,2 . Auflage 1830) nur noch unkritische Nachdrucke erlebt, die alle keine Verbesserungen der 2. Auflage darstellen (3. Auflage 1835,4 . Auflage 1842 , 5. Auflage 1861,6 . Auflage 1884 , außerdem Bibliothek theologischer Klassiker Band 13-16 1889; Hendels Bibliothek der Gesamtliteratur Band 1027-1038, 1897). Diese Nachdrucke reproduzieren alle kritiklos den Text der 3. Auflage, die als Teil der Gesamtausgabe der Werke Schleiermachers eine pseudo-kanonische Gültigkeit erhielt, obwohl sie eine Reihe von Flüchtigkeitsfehlern aufweist. Die weiteren Auflagen, besonders aber die letzte, 6 . Ausgabe, vermehren diese Fehler durch eine große Anzahl von teilweise recht sinnstörenden Druckfehlern (z. B. $\int_{3}$ u. a.).

Die vorliegende Neuausgabe geht auf die 2. Auflage zurück, da sie die Fassung darstellt, die der Autor als letzte hinterlassen hat. Der Text dieser Ausgabe wird noch ergänzt durch die handschriftlichen Anmerkungen zu den $\iint_{1-8} 5$ des ersten Teiles, die Schleiermacher selber in einem Exemplar der Glaubenslehre hinterlassen hat, das er anscheinend zum $Z$ wecke seiner Vorlesungen vermutlich letztmalig 
1830 benutzt hat und die Thönes herausgegeben hat. Diese Anmerkungen werden, da es sich um originale Äußerungen Schleiermachers handelt, in einem besonderen Apparat unterhalb des Textes geboten. Es läge nahe, den Neudruck der 2. Auflage durch eine Synopse mit der 1. Auflage zu ergänzen, weil der Text der I. Auflage zweifellos wichtige Hinweise für die Interpretation beider Auflagen gibt. Carl Stange hat eine solche Synopse für die Einleitungskapitel (1. Auflage

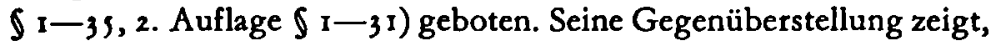
wie groß die Unterschiede in der Textgestaltung der beiden Auflagen sind, wenn auch die sachlichen Differenzen, auch nach Schleiermachers eigenen Aussagen, nicht allzu bedeutend sind. Wegen dieser groBen Unterschiede im Wortlaut und auch im Aufbau des Werkes ist eine voll durchgeführte Synopse des Gesamtwerkes schwierig und für den Leser voraussichtlich verwirrend.

Schleiermacher selbst gesteht seinem Freunde GaB am 12 . November 1829: „bis jetzt ist (bei der Neubearbeitung der Dogmatik) noch kein Paragraph ganz stehen geblieben wie er war, sondern ich schreibe durchaus alles neu. In der Sache freilich bleibt alles dasselbe" (Schleiermachers Briefwechsel mit Gaß, Berlin 1852, S. 219-220). Schleiermacher hat in der Tat in der 2. Ausgabe fast alles neu formuliert und dabei doch auf den Text der x. Auflage Rücksicht genommen. Einige etwas verunglückte Satzkonstruktionen der 2. Auflage, z. B. $\ 27$ Abs. 2, lassen noch erkennen, daß ihm das in der Eile nicht immer völlig gelungen ist. In der 1 . Auflage spricht Schleiermacher unbefangener und unmittelbarer das aus, was ihm eigentlich vorschwebt, und auch der Aufbau der I. Auflage ist konsequenter und ursprünglicher als der der 2. Auflage. In der späteren Auflage nimmt er Rücksicht auf die Einwände seiner theologischen Gegner und Freunde. Um die Besonderheit dieses Aufbaues der beiden Ausgaben zu kennzeichnen, wird deshalb im Anhang eine synoptische Gegenüberstellung der Leitsätze beider Ausgaben geboten.

Für das Verständnis der I. Auflage und für die Erkenntnis der Absichten Schleiermachers bei der Neubearbeitung seiner Glaubenslehre, die am Ende der zoer Jahre erfolgte, sind auch handschriftliche Anmerkungen Schleiermachers wichtig, die uns in einem mit Schreibpapier durchschossenen Exemplar der 1. Auflage der Glaubenslehre überliefert worden sind. Diese zum Teil sehr schwer lesbaren Marginalien Schleiermachers mit sehr vielen Hinweisen auf seine Auseinandersetzung mit seinen Kritikern und dem Versuch, seine Grund- 
intentionen präziser zu formulieren, sind noch nicht veröffentlicht worden.

Der Herausgeber wird aber im Zusammenhang der erwähnten Synopse einige der wichtigsten Stellen bereits schon vor der beabsichtigten Gesamtveröffentlichung mitteilen.

In einer kritischen Ausgabe waren natürlich auch die Zitate Schleiermachers und die Hinweise auf Stellen in der Heiligen Schrift zu überprüfen. Es stellen sich dabei eine Reihe von Flüchtigkeitsfehlern heraus. Man muß aber bedenken, daß man zur Zeit Schleiermachers noch nicht dieselben Anforderungen an die Genauigkeit des Zitierens stellte wie heutzutage. Bezeichnend ist, daß sogar das Motto auf der Titelseite, ein Zitat aus Anselms Proslogion de Dei existentia (credo ut intelligam) einen Flüchtigkeitsfehler enthält, der erstaunlicherweise in allen Ausgaben der Glaubenslehre mitgeschleppt wurde. Statt der Abkürzung Proslog(ion) heißt es versehentlich Prosol. Aus den Zitaten geht hervor, daß Schleiermacher neben den Bekenntnisschriften und Melanchthons Loci vornehmlich sich mit Calvin, Quenstedt und Johann Gerhard beschäftigt hat, wie er das ja auch bereits in einem Briefe aus dem Jahre $181 x$ bei der Neuanfertigung seines Dogmatik-Kollegs hervorhebt. Die Lutherzitate entstammen hauptsächlich dem Genesiskommentar Luthers, also einer Spät-Vorlesung Luthers, von der nicht einmal genau feststeht, ob sie nicht von Melanchthonschülern so stark überarbeitet worden ist, daß die original-lutherischen Gedanken verdeckt worden sind. Am häufigsten sind die Zitate aus den Schriften Augustins, dem er sich zweifellos verwandt gefühlt hat.

Um die Benutzung dieser Neuausgabe zu erleichtern, sind die Seitenzahlen der von Schleiermacher noch besorgten 2. Ausgabe am Rande vermerkt. Im Anhang wird eine synoptische Gegenüberstellung der verschiedenen Seitenzahlen der einzelnen Ausgaben geboten. 


\section{DIE ENTSTEHUNG}

\section{DER GLAUBENSLEHRE SCHLEIERMACHERS}

Die Glaubenslehre ist aus den Vorlesungen Schleiermachers hervorgegangen. Er beabsichtigt schon früh, eine Dogmatik als Handbuch für seine Vorlesungen zu veröffentlichen. Schon am r. Dezember 180 ) berichtet er seinem Freunde Willich, daß er für seine Vorlesungen in ein paar Jahren ein kleines Handbuch der Dogmatik drucken lassen wolle. Er prophezeit allerdings, daß es dann den Juden ein Argernis und den Griechen eine Torheit sein werde (Br. II, Seite 44).

Die nicht sehr zahlreichen Berichte in seinen Briefen lassen erkennen, wie sehr er mit der neuen Aufgabe, auf dem Gebiete der wissenschaftlichen Glaubenslehre einen völlig neuen Ansatz zu wagen, gerungen und wie er erst allmählich zu seinen epochemachenden Erkenntnissen vorgedrungen ist.

Die beiden ersten dogmatischen Vorlesungen fallen in das Wintersemester $1804 / 0$ s und das Wintersemester 180 s/06 an der Universität Halle. Das erste Kolleg hielt er über die Haupt- und Fundamentallehre des theologischen Systems (Intelligenzblatt der allgemeinen Literaturzeitung Halle 1804 Nr. 1 (5). Der junge Professor beurteilt seine eigene Leistung zunächst recht kritisch. „Das Fundamentale hat mir anfangs am wenigsten genügt, jetzt lebe ich mich besser hinein, und wenn ich es auch in dieser Gestalt nicht sobald wiederhole, so enthält es doch die Keime, teils eines größeren kritischen Kollegiums über die Dogmatik, teils manches Exegetische, was ich doch gewiß in der Zukunft lesen werde." Mit seiner gleichzeitig gehaltenen Vorlesung über die philosophische Ethik ist der Dozent selber viel mehr zufrieden. (Briefe an Gaß, S. 3).

Von Anfang an bietet der Professor Schleiermacher seinen Hörern einen völlig freien mündlichen Vortrag auf Grund einiger Notizen. Erst hinterher schreibt er seine Vorlesungen auf, gesteht aber, da $\mathrm{B}$ er oft mit diesem Schreiben nicht weit kommt, weil er am liebsten spricht und nicht schreibt (Briefe an Gaß 1804, S. 2). Diesen 
Brauch hat Schleiermacher sein Leben lang beibehalten. Seine Schüler und Hörer rühmen daher die Lebendigkeit seines Vortrages, gestehen aber, daß es oft schwierig ist, bei ihm ein gutes Kolleg nachzuschreiben (Lücke). Sein Gedankenfortschrittt nimmt oft nicht viel Rücksicht auf das Auffassungsvermögen des einfacheren und mittelmäßig begabten Studenten. Er macht es seinen Zuhörern schwer, weil er den Gegenstand von vielen Seiten beleuchtet, in dialektischem Stil sich selber Einwände macht, um sie zu widerlegen. In kritischer Weise hat das David Friedrich Strauß auf Grund eigener Erlebnisse anschaulich geschildert ${ }^{1}$. Viele Studenten hören daher lieber seine Predigten, weil sie eine einfacher aufgebaute Darstellung der christlichen Glaubensgehalte für die Gemeinde sind, während seine Vorlesungen sich allzu häufig in ein sehr geistreiches und vielschichtiges Gespräch des Professors mit sich selber verlieren. So geht es dem jungen Wichern, der von den Vorlesungen Schleiermachers weniger, aber um so stärker von den Predigten beeindruckt ist. (Briefe und Tagebuchblätter I. Bd. S. 116 f.)

1 Vgl. David Friedrich Strauß: Gesammelie Schriften s. Band. Nach des Verfassers letztwilligen Bestimmungen zusammengestellt, eingeleitet und mit erklärenden Nachweisen versehen von Eduard Beller. Verlag von Emil Strauß, Bonn 1877 .

Der Cbristus des Glaubens und der Jesus der Gesebicbte. (Eine Kritik des Schleiermacherschen Lebens Jesu.)

Einleitung: S. 7-9: „Schleiermacher trug bekanntlich frei, höchstens nach ganz summarischen Entwürfen, vor, wie er auch seine Predigten, nach einiger vorgängigen Meditation, auf der Kanzel frei zu produzieren pflegte. Die Zahl seiner Zuhörer in Kirche und Hörsaal, die tiefe und nachhaltige Anregung, die sie von ihm erfuhren, das unauslöschliche Andenken, das sie seinen Vorträgen bewahren, sind ebensoviele Beweise, daB er hierin Außerordentliches geleistet hat. Aber man mußte sich an seine Manier erst gewöhnen. Was mich betrift, so hatte ich allerdings, als ich nach Beendigung meiner Universitätsstudien von Tübingen nach Berlin kam, von einem freien Vortrag überhaupt noch keine Erfahrung. D2für aber war ich durch genaue Kenntnis von Schleiermachers Schriften und durch philosophische Studien mehr als seine gewöhnlichen Zuhörer auf seine Vorlesungen vorbereitet. Dennoch wurde es mir nicht leicht, mich in seine Art 24 finden, und eigentlich befriedigt hat er mich nach halbjähriger Probe auf der Kanzel mehr als auf dem Katheder. Die allgemeinen Mängel, die mehr oder minder jedem freien Vortrag anhaften und die man die stilistischen im weiteren Sinne nennen könnte, waren seinen Kanzel- und Kathedervorträgen gemein und wurden durch die Lebendigkeit seiner mündlichen Vorträge mehr als gut gemacht. Der besondere Mangel seiner Kathedervorträge lag in eben dem Punkte, worin zugleich ihr Vorzug lag, nämlich darin, daB seine Methode dabei ausschlieBlich die dialektische war. An sich, was kann für den Zuhörer lehrreicher scin, als wenn 
Schleiermacher bezeichnete es als Endzweck seiner ersten dogmatischen Vorlesung in Halle, daß sie die Leute lehre, unter dem Begriff die Idee zu suchen (Briefe II, S. 9). Das ist ihm überhaupt das Anliegen der Theologie: „Lege man immer den Gemütern, die durch das törichte Streiten über den Buchstaben und die dialektische Frechheit des leeren Räsonnierens irre geworden, die Idee ans Herz, so wäre es wunderbar, wenn man dem Christentum nicht Freunde ge-

ihm der Lehrer Nichts in Form einer toten Notiz, sondern Alles als Problem vorlegt, dessen Lösung sie nun gemeinschaftlich suchen gehen? Wenn er ihm seine Gedanken nicht als fertige überliefert, sondern sie vor ihm werden, wachsen, sich verwickeln und entwickeln läßt? Lobt man nicht in wissenschaftlichen Schriften vor allem die genetische Darstellung? Aber zwischen ihr und jener Vortragsweise ist noch ein wesentlicher Unterschied. Die genetische Darstellung geht von dem schon gewordenen Gedankenganzen aus und stellt dieses in seinem Werden dar, aber nicht, wie es wirklich geworden ist, wobei es ohne allerhand Zufälligkeiten und Unregelmäßigkeiten nie abgeht, sondern so, wie es eigentlich hätte werden sollen: die genetische Darstellung ist, wie jede künstlerische oder wissenschaftliche, eine ideale. In ihr ist Schleiermacher in seinen von ihm selbst herausgegebenen Schriften ein unübertroffener Meister, und eben auf dieser Eigenschaft berubt das unvergleichlich Anregende und Lehrreiche, was wir an ihnen kennen. Sprach er hingegen vom Katheder, so hatte er freilich die allgemeinen Ergebnisse auch schon fertig und die Gedankengänge, mittelst deren er zu denselben gelangt war, für sich schon oft durchlaufen; aber nun sollten diese Gedankenreihen, die er in der Muße des Studierzimmers gesponnen hatte und bei ruhiger, schriftlicher Ausarbeitung in aller idealen Regelmäßigkeit dargestellt haben würde, in rascher, mündlicher Improvisation neu hervorgebracht werden. $D_{2} B$ hiebei der Zufall seine Rolle spielte, die fein gesponnenen Fäden sich bisweilen verwirtten, die verwirten abgerissen wurden, die ganze Darstellung keineswegs das Gepräge der Ordnung und Regelmäßigkeit, sondern stellenweise sogar das der Zerfahrenheit oder Verworrenheit trug, liegt in der Natur der Sache. In Betreff des Predigens gibt Schleiermacher selbst einmal (Predigten, erste Sammlung, Nachschrift zu der Zueignung) den Rat, der Redner von ruhigerem Naturell möge, ohne den Buchstaben bestimmt ausgearbeitet und ins Gedächtnis gefaßt zu haben, die Kanzel besteigen, der beweglichere dagegen sich lieber von Anfang an das vorher geschriebene Wort binden, um so zu der Ruhe und Mäßigung zu gelangen, welche dem Zuhörer das klare Auffassen erleichtert. Schleiermacher stand seiner Natur nach entschieden auf der Seite der höchsten Lebendigkeit und quecksilberartigen Beweglichkeit; auf der Kanzel hatte diese in dem Gefühlston, der doch immer eine gewisse Getragenheit mit sich bringt, ein Gegengewicht; auf dem Katheder fiel dieses hinweg, und da überließ er sich einer Rastlosigkeit im Aufnehmen und Wiederfallenlassen der Probleme, im Anfassen ciner Sache bald ron der, bald ron jener Seite, die dem Zuhörer Schwindel erregen konnte, wenn nicht die lebendige, stets treffende und anschauliche Rede des gegenwärtigen Lehrers ihn an der Hand gehalten und auch über die Klüfte der Darstellung hülfreich mit hinübergerissen hătte." 
winnen könnte" (Briefe II, S. 9). Im Gegensatz zu dem Streiten über Buchstaben, der überlieferten Lokalmethode des altprotestanrischen Schriftbeweises und dem rationalistischen Beweisenwollen der aufklärerischen Populardogmatik bedeutet für ihn das Suchen nach der Idee die Frage nach dem Wesen des Christentums.

Die zweite dogmatische Vorlesung in Halle im Wintersemester 1805/06 trägt bereits die Bezeichnung "Christliche Glaubenslehre“, ein Titel, der später zu der charakteristischen Selbstbezeichnung seiner theologischen Hauptschrift wurde. Er liest die Glaubenslehre aber nach einem theologischen Lehrbuch von Ammon (Christoph Friedrich Ammon, Summa theologiae Christianae, 1802). Der junge, inzwischen zum Ordinarius aufgerückte Professor hat in seinen dogmatischen Vorlesungen zunächst verhältnismäßig geringen Erfolg. Er berichtet von einer Mandel (is) Hörer, während er in der philosophischen Ethik so Zuhörer und in seinem Publikum über den Galaterbrief 120 Hörer registrieren kann. Dazu bemerkt Schleiermacher: "Sie trauen mir noch nicht recht, ob meine ketzerische (ich meine hier bloB das reformierte, wiewohl auch von ihr als von einer Schellingianischen gesprochen worden ist) Dogmatik, die noch dazu nur ein halbes Jahr dauert, auch passieren wird in den testimoniis und vor dem Konsistorio" (Briefe an GaB, S. 37).

Der Vorwurf, daß er unter dem Einflu $B$ von Schelling steht, hat für die Hallesche Zeit zweifellos eine gewisse Berechtigung. Das einzige öffentliche Zeugnis aus dieser Periode, die Weihnachtsfeier von 1806 , läßt in ihren halb künstlerischen Dialogen erkennen, wie Schleiermacher vorübergehend Gedankengut aus der Metaphysik von Schelling übernommen hat. Der Gesprächsbeitrag von Eduard in der Weihnachtsfeier läßt das deutlich erkennen. Bereits die Endlichkeit des Menschen ist Abfall von Gott, aber Christus, als das göttliche Prinzip in der menschlichen Natur, bringt die Erlösung zur neuen Lebenswahrheit des Geistes. Beide Gedanken hat Schleiermacher später widerrufen (vgl. Glaubenslehre, 2. Aufl. $\$ 69$, Abs. 3). In einer Rezension in der Jenaer Literaturzeitung von $1806 \mathrm{Nr}$. Ior bezeichnete Schleiermacher es als die Aufgabe der Dogmatik, die Dogmen aus dem religiösen Gefühl zu entwickeln und die Dogmen dann mit den Aussprüchen der reinen Spekulation zusammenzustellen.

Im Winter 1809 beginnt Schleiermacher noch vor der Eröffnung der Universität Berlin, die 1810 erfolgte, zusammen mit Fichte und anderen, wohl in der alten Akademie, Vorlesungen zu halten und trägt 
dabei eine Darstellung der christlichen Glaubenslehre vor, die „nicht nur für Theologen berechnet, aber zugleich eine spekulative Kritik" der Glaubenslehre war. So zeichnet sich hier bereits in den Anfängen ein doppeltes Anliegen seiner Dogmatik ab: einen möglichst unmittelbaren Ausdruck der christlichen Glaubenserfahrung zu gestalten und ihn dann in der Auseinandersetzung mit den geistigen Mächten der damaligen Zeit in Begegnung und Unterscheidung kritisch zu prüfen.

Im ersten Semester innerhalb der neu eröffneten Berliner Universität, im Wintersemester $1810 / 11$, trägt Schleiermacher seine theologische Enzyklopädie vor, und erst im Sommersemester 18 Ir hält er eine Vorlesung mit der Bezeichnung: Dogmatische Theologie nebst vorausgeschickten philosophischen Untersuchungen über die christliche Religion. Damals berichtete er seinem Freunde GaB, daß er diese Einleitung in die Dogmatik völlig neu bearbeitet habe und alles hierher Gehörige aus der philosophischen Theologie beigebracht habe (Briefe an Gaß, S. 94). Ferner erwähnt er, daß er bei seiner Kollegvorbereitung in Halle die altprotestantische Dogmatik von Quenstedt und jetzt in Berlin das System von Johann Gerhard ,verglichen habe". Außerdem stöhnt er tüchtig darüber, wieviel Mühe und Arbeit ihm die Vorbereitung für seine exegetischen Vorlesungen und vor allen Dingen für die zum ersten Male vorgetragene Dialektik bereite. Bezeichnend ist dabei auch der Hinweis: „Zum Aufschreiben (gemeint ist das nachträgliche Aufschreiben der dogmatischen Vorlesungen) bin ich aber gar nicht gekommen und muß mich auf Pischon verlassen, der zu meiner Freude sehr gut nachschreibt. " Der Berliner Gelehrte wiederholt seine Dogmatik-Vorlesungen in dem Wintersemester $1812 / 13$, S. S. 1816 , S. S. 1818 , W. S. $1818 / 19$, W. S. $1820 / 21$, S. S. 1821 , S. S. 1825 und nennt sie im Vorlesungsverzeichnis schlicht Dogmatik. Nur im Wintersemester $1823 / 24$ kündigt er an: Christliche Glaubenslehre nach dem Buche: Der christliche Glaube, das 1821 erschienen war; ebenso im W. S. $1827 / 28$. Seine letzte dogmatische Vorlesung im Sommersemester 1830 nennt er: Dogmatische Theologie nach dem Buche: Der christliche Glaube. Vermutlich hat Schleiermacher sich bei Ankündigung und Bezeichnung seiner Vorlesungen von dem üblichen akademischen Sprachgebrauch leiten lassen, während er in der Titelformulierung seines Buches seine besondere Konzeption dieser Disziplin zum Ausdruck brachte. Schleiermacher nat also die Dogmatik in dreizehn Universitätssemestern gelesen. Sie ist seine Hauptvorlesung gewesen. Von 
seinen übrigen exegtischen, historischen, philosophischen systematisch-theologischen und praktisch-theologischen Vorlesungen hat er am meisten die Enzyklopädie und die christliche Sittenlehre bevozzugt, die er beide zwölfmal gelesen hat.

Während er von 181 I bis 1821 der Dogmatik-Vorlesung im Sommersemester, Wochenstunden widmete, dehnte er seit 1823 diese Vorlesung auf 10 Wochenstunden aus, die er im Sommer von 7 bis 9 und im Winter von 8 bis $10 \mathrm{zu}$ halten pflegte. Im Sommersemester ging dieser Dogmatik-Vorlesung meist noch ein philosophisches Kolleg über Dialektik oder Psychologie voraus, das er in der ungewöhnlich frühen Zeit von morgens 6 bis 7 Uhr abhielt. Das ist eine enorme Arbeitsleistung, wenn man bedenkt, daß er neben seiner Vorlesungstätigkeit eine erhebliche literarische Produktion aufzuweisen hat, da $B$ er sonntäglich im Gottesdienst der Dreifaltigkeitsgemeinde predigte, daß er Mitglied und Sekretär der Akademie der Wissenschaften war und $\mathrm{da} B$ er sonst eine Reihe von anderen Verpflichtungen auf sich nahm. Im Jahre 181 s/16 war er Rektor der Universität und in den Jahren $1810 / 11,1813 / 14,1817 / 18,1819 / 20$, also viermal, Dekan der Theologischen Fakultät. Interessant ist es auch, einen Uberblick zu bekommen über die Zahl der Studenten, die zu seinen Füßen saßen. Die Zahl der Theologiestudenten bei der Eröffnung der Universitāt im Wintersemester $1810 / 1$ I beträgt 29 gegenüber einer Gesamtzahl der Studenten der Universităt von 256 (etwa $11 \%$ Theologiestudenten). Im Wintersemester $1813 / 14$ geht die Zahl der Theologiestudenten auf, und die Gesamtzahl der Studenten aller Fakultäten auf 28 zurück. Ab $1817 / 18$ nimmt die Zahl der Theologiestudenten mit der Gesamtzahl der Studenten der Universität zu. 1820 hat die Berliner Theologische Fakultăt 161 Hörer bei 910 Studenten der Universität. Den Höhepunkt ihrer Hörerschaft zu Schleiermachers Lebzeiten erreicht die Berliner Theologische Fakultät $1830 / 31$ mit 641 Hörern gegenüber einer Gesamtsumme der Studenten von 2488. Die Theologenzahl betrāgt also 25,8\% der Gesamtzahl aller Studenten. Dieser Erfolg der Berliner Theologischen Fakultät ruht zweifellos auf dem wachsenden Lehrerfolg und der immer größer werdenden Anziehungskraft der Persönlichkeit Schleiermachers. Auch der Prozentsatz der Theologen an der Gesamtsumme aller Studenten ist erheblich hoch, man braucht damit nur zu vergleichen, daß z. B. im Jahre 1905 nur noch 4,05\% der Gesamtzahl der Studenten der Universität Berlin Theologen waren. 
Der Weg von den Reden über die Religion und den Monologen bis zur Glaubenslehre von $182 \mathrm{I}$ ist weit. Es ist die Entwicklung des jungen Predigers an der Charité in Berlin bis hin zum Theologieprofessor an der Universität Berlin und dem damals maßgeblichen Dogmatiker der evangelischen Kirche. Die Entwicklung seiner speziellen dogmatischen Anschauung läßt sich ziemlich schwer schildern. Am besten kennen wir die neue theologische Konzeption des jungen Schleiermacher und dann wiederum das reife theologische System der Glaubenslehre in den beiden Auflagen von 1821 und 1830. Die Entwicklung dagegen in den dazwischen liegenden Jahrzehnten von 1800 bis 1821 bzw. 1830 , ist uns trotz mancher Anhaltspunkte in seinen Briefen und auch in seinen Veröffentlichungen nur zum Teil bekannt. Schleiermacher hat vermutlich bei dem Erscheinen seiner Glaubenslehre 1821 seine früheren Aufzeichungen und Vorlesungsmanuskripte vernichtet; denn es ist uns aus dieser Zeit nichts von diesen dogmatischen Entwürfen erhalten geblieben. Wir kennen nur seine Weihnachtsfeier, seine Enzyklopädie, die 1811 erschien, und außerdem haben seine Vorlesungsnotizen für sein Kolleg über Dialektik, das er $1811,1814,1818$ und dann wieder 1822,1828 und $183 \mathrm{I}$ hielt, eine gewisse Bedeutung für die Erkenntnis seiner Gedankenbildung. Wir besitzen dann noch einige handschriftliche Anmerkungen, die er in einem Exemplar der Glaubenslehre von 1821 uns hinterlassen hat. Sie stammen vermutlich aus den Jahren $1823 / 24$, 1825, in denen er über die Dogmatik las, und aus dem Ende der zwanziger Jahre, als er an der Neuausgabe der Glaubenslehre arbeitete. Sie sind sehr schwierig zu entziffern und daher bisher noch nicht veröffentlicht worden.

Für das Verständnis der Entwicklung seiner dogmatischen Anschauungen sind wir daher in erster Linie auf seine Enzyklopädie (1811, 2. Auflage 1830 ) angewiesen. Sie ist ein Zeugnis dafür, wie Schleiermacher sich seinen Weg für die Dogmatik sucht und in schwerer Bemühung findet. Bisher ist viel zu wenig beachtet werden, daß er bereits hier die Theologie als positive Wissenschaft von der philosophischen Spekulation unterscheidet, wobei ganz besonders hervorzuheben ist, daß diese philosophische Metaphysik für Schleiermacher und seine Zeit die eigentlich maßgebende, primäre Wissenschaft ist gegenüber den sekundären positiven Einzelwissenschaften. Das bedeutet für seine theologische Grundkonzeption, daß die Theologie ihren Gegenstand und ihre Erkenntnis nicht aus allgemein-metaphy- 
sischen Prinzipien ableiten kann, sondern da $B$ ihr ihr Gegenstand gegeben ist. Das liegt in der Bezeichnung positiv, die nicht als das Pendant zu dem Begriff negativ zu verstehen ist, vielmehr als das "positiv" Gegebene, das Gegenstück minderen Ranges gegenüber dem Metaphysischen, Allgemeingültigen und nicht empirisch Gegebenen anzusehen ist. Die Philosophie hat zum Gegenstand den universalen Logos. Die Theologie aber wendet sich dem Glauben zu, weil sich in diesem Glauben und durch den Glauben der Geist Gottes den Menschen offenbart. Nur dieser Glaube ist lebendig und als geschichtliche Größein der christlichen Kirche wirksam. Für diese Kirche ist auch die konfessionelle Trennung in römisch-katholisch und evangelisch wesentlich, während die Differenzen zwischen den Lutheranern und Calvinisten für die gemeinsame lebendige Verkündigung der Kirche sekundär sind. Die Theologie ist daher die Selbstdarstellung des christlichen Glaubens mit Hilfe der Begrifflichkeit wissenschaftlichen Denkens. In den $\iint 84$ und 313 der Enzyklopädie wird das deutlich ausgesprochen. Die Theologie hat den Zweck: die Idee des Christentums nach der eigentümlichen Auffassung der evangelischen Kirche in ihr immer reiner zur Darstellung zu bringen. Da es sich zunächst darum handelt, die in der Kirche tatsächlich vorhandene, lebendige Verkündigung in ihrem Gesamtgehalt darzustellen, ist die Dogmatik eine historische Disziplin. Sie soll die in der christlichen Kirche tatsächlich vorhandene innere Glaubenserfahrung, die, wie Schleiermacher sagt, christlich frommen Gemütszustände, zum Gegenstand haben und sie in kritischer Phänomenologie beschreiben, prüfen, läutern und weiterbilden. Diese Darstellung soll orthodox sein, weil sie das Erbe der Lehrtradition wahren soll, heterodox aber, um auch neuen Fragestellungen den ihnen zukommenden Platz einzuräumen. Maßstäbe für die Kirchlichkeit und Echtheit dieser Verkündigung sind der neutestamentliche Kanon, die reformatorischen Symbole, aber auch hier schon die Gewißheit des unmittelbaren, frommen Selbstbewußtseins. Da diese Darstellung, wie sofort ersichtlich, nicht eine rein empirische Bestandserhebung und Beschreibung sein kann, ist die Frage nach dem eigentümlichen Wesen des christlichen Glaubens auch für die Dogmatik als historische Disziplin von hoher Bedeutung. Damit hängt ohne weiteres zusammen die Auseinandersetzung der christlichen Glaubenserkenntnis mit dem allgemeinen menschlichen Wahrheitsbewußtsein in den sonstigen Bereichen menschlichen Geisteslebens. Diesen Fragenkomplex überweist 
Schleiermacher der philosophischen Theologie. So hat bereits nach der Enzyklopädie die dogmatische Systembildung Schleiermachers ein doppeltes Gesicht. Als das eigentliche Anliegen wird bezeichnet, die christliche Glaubenserfahrung unabhängig und ohne Rücksicht auf die metaphysische Spekulation zum Ausdruck zu bringen, auf der anderen Seite ergibt sich aber doch die Notwendigkeit eines Gespräches und einer Auseinandersetzung mit dem allgemeinen menschlichen Wahrheitsbewußtsein, um die Eigentümlichkeit und die Selbstgewißheit der christlichen Glaubenserfahrung und Glaubenserkenntnis zu stärken und zu festigen und zu bestätigen. Interessant ist bereits, da $B$ im $\ 240$ die Wahrheit des SelbstbewuBtseins, die es nach Schleiermachers Grundkonzeption mit der Wahrheit des christlichen Glaubens zu tun hat, dem objektiven Bewußtsein, also dem gegenständlichen Wissen, gegenübergestellt wird. In Verfolg dieser doppelten Ausrichtung der dogmatischen Systembildung ist er bereits auch in der Enzyklopädie bemüht, die Theologie, deren Eigenständigkeit durch ihren Gegenstand und ihre Methode festgestellt ist, auf der anderen Seite in das Gefüge der übrigen Wissenschaften einzuordnen. Schleiermacher glaubt an die Einheit der geistigen Welt und ist erfüllt von der Gewißheit, daß diese Einheit der geistigen Welt gerade von der Theologie, von der ersten Fakultät der universitas literarum, begründet wird $(\$ 21)$. Gerade in der Begegnung mit den übrigen Bereichen menschlichen Geistes will er die Eigenart des Christentums in Begegnung und Unterscheidung charakterisieren. Er will nicht spekulativ deduzieren, er will aber auch nicht bloß empirisch beschreiben, sondern er will in kritischer Verstehensanalyse und phänomenologischer Wesensschau das besondere Wesen des christlichen Glaubens bestimmen. So zeigen sich bereits hier die Grundlinien seines späteren Systems.

Sehr viel schwieriger als die Auswertung seiner Enzyklopädie ist die Beurteilung der Bedeutung der Anfänge seiner philosophischen Gedankenwelt für die Entstehung seines dogmatischen Systems. Man kann wohl nicht leugnen, daß in den uns vorliegenden, unfertigen und von Schleiermacher selbst stark kritisierten Anfängen seiner Dialektik von $18 \mathrm{I} 1$ und auch in seinem Vorlesungsmanuskript von 1814 nicht nur eine Begegnung mit dem identitätsphilosophischen Denken seiner Zeit erfolgte, sondern auch ein Einbruch dieser Metaphysik in Schleiermachers geistige Welt. Der Berliner Professor bezeichnet Gott in seinen philosophischen Kollegs als den transzen- 
denten Grund des Seins. Gott ist hier der Name für die Einheit, Harmonie und Macht des Seins. Er ist das eigentliche Zentrum des Seins, der schöpferische Urgrund. Die antike Formulierung, daß Gott Einheit und Allheit sei (hen kai pan), trifft auf Schleiermacher nicht zu. Dagegen wäre in seinem Sinne so zu formulieren: Gott ist die Einheit als Urgrund der Vielheit (pan di henos). Es darf auch nicht vorschnell übersehen werden, daß der Berliner Gelehrte in den Anfängen seiner philosophischen Systembildung bereits sehr deutlich zwischen Gott und Welt unterscheidet. Die Welt ist die Totalität der Vielheit, der Endlichkeit, der Mannigfaltigkeit und Vergãnglichkeit. Gott aber ist die schlechthin überlegene Einheit, die dem Denken des Menschen unzugänglich ist und durch das Denken des Menschen nicht begründet werden kann. Der Glaube des Menschen ist niemals auf die Allheit der Welt bezogen, sondern nur auf den schöpferischen Urgrund der Einheit, und darum ist in diesen philosophischen Anfängen die Religion Einheitsbcwußtsein als Voraussetzung alles geistigen Denkens und Philosophierens, eine Voraussetzung, die selber niemals Gegenstand des menschlichen Denkens und Suchens sein kann, sondern eben nur nicht beweisbare Voraussetzung. Der Quell der Wahrheit ist nicht in uns, sondern über uns, jenseits von uns (G. Wehrung, Die Dialektik Schleiermachers 1920 S. 311 ). Es ist weiter nicht zu leugnen, und darauf hat bereits Wehrung mit Recht hingewiesen, daß Schleiermacher in der Weiterbildung seiner philosophischen Gedanken die identitätsphilosophische Ontologie und Kosmologie zurückdrängt. Dafür ist bereits die Dialektik von 1822 Zeuge. Der Gedanke Spinozas, daß Gott die natura naturans sei, also der schöpferische Urgrund, wird jetzt 1822 deutlich abgelehnt (Dialektik, 416f.). Der Gottesgedanke hat sich aus der „immanenten Umklammerung“ losgerungen (Wehrung, S. 190). Der Schöpfungsgedanke gewinnt die Oberhand, und daher die Úberzeugung, daßGott die Urkausalität, also die Voraussetzung des Kausalzusammenhanges der Welt ist und nicht nur der schöpferische Seinsgrund. Das fromme Einheitsbewußtsein wird durch das ursprüngliche Abhängigkeitsgefühl verdrängt. Die Bedeutung dieser Gedanken Schleiermachers wird noch viel klarer ersichtlich, wenn man erwägt, daß er sich mit dieser Gedankenbildung in scharfen Widerspruch zur Vorherrschaft der Spekulation bei Hegel setzt und den Vorstufencharakter der Religion ablehnt. In diesem Sinne ist die Bemerkung auf Seite 9 der r. Auflage der Glaubenslehre 
zu verstehen, daß Philosophisches und Dogmatisches nicht vermischt werden dürfe. Der Glaube wird nicht durch die Vernunft begründet. Die Vernunft hat überhaupt keine fundierende Funktion, sondern ist eine fundierte Funktion. Aber das Nachdenken des Glaubens über sich selbst, der Ausdruck der frommen Gemütszustände, bedarf der philosophischen Sprache, der dialektischen Beschaffenheit der menschlichen Sprache und der Einordnung in den Zusammenhang des menschlichen Geisteslebens (Glaubenslehre, I. Auflage, S. 196). Die Trennung der Dogmatik von der Philosophie kann nie so weit gehen, daß sie auch der philosophischen Sprache entsagen müßte.

Ist diese Empfehlung ganz harmlos? Die sachliche Anlehnung der Glaubenslehre an die Dialektik verleiht der theologischen Glaubenslehre ihre möglichst strenge wissenschaftliche Gestaltung (Glaubenslehre, S. 195). Schleiermacher verwirft die Besorgnis, daß sich dabei doch die Philosophie zur Richterin über die theologische Sache aufwirft. Die Religion ist also in ihrem Leben, ihrem Entstehen und in ihrer Selbstprüfung und Selbstrechtfertigung eigenständig gegenüber der Philosophie. Aber die Deutung und Auslegung, die Lehre, ist dennoch vom höchsten Wissen abhängig. Ob sich das nicht doch auch im Religionsbegriff ausprägt? Bereits die Ritschlianer haben den Vorwurf wiederholt, daß infolge dieser Unterwerfung der theologischen Lehre unter die philosophische Begrifflichkeit der Religionsbegriff Schleiermachers ungeschichtlich würde und der $\mathrm{Zu}$ sammenhang von heilsgeschichtlicher Offenbarung und menschlicher Glaubenserfahrung gehemmt würde (Wilhelm Hermann). Schleiermacher selbst hat dann später in seinem Sendschreiben an Lücke diese Frage neu aufgegriffen und für sich in Anspruch genommen, eine Eigenständigkeit und theologische Begriffsbildung dadurch zu schaffen, daB er die philosophische Sprache umwandele und dem theologischen Gegenstand und der theologischen Erkenntnismethode assimiliere. Soweit ist er aber in der Enzyklopädie und auch in den Anfängen seiner Dialektik jetzt noch nicht.

Welche Bedeutung hat seine allmählich zur Bewußtheit sich durchringende Philosophie für seine Dogmatik, die ungefähr gleichzeitig sich in jahrelanger Arbeit entfaltete, bis sie dann 1821 veröffentlicht wurde? Ist dabei nicht die Tatsache zu berücksichtigen, daß seine philosophische Wissenschaftslehre, die Dialektik, nicht mehr von 
Schleiermachers Hand die abschließende Gestaltung erhielt, so daß er sie selber nicht als Buch herausgeben konnte?

Schleiermachers eigene Aussagen in seinem Brief an Jacobi vom 30. März 1818 und in seinem Sendschreiben an Lücke betonen zunächst leidenschaftlich, $\mathrm{da} B$ er in seiner Glaubenslehre eine Darstellung der christlichen Glaubenserfahrung geben wolle, die völlig unabhängig von jeder philosophischen Spekulation sei. Die Religion ist nicht, wie die Rationalisten fälschlich behaupteten, eine „'Tochter der Theologie“. Es darf nicht ein neues „Priestertum der Spekulation“ entstehen, das sich über die Frömmigkeit des unspekulativen Volkes erheben will. Der kirchliche Dienst am Wort hat dagegen zur Aufgabe: „Eine klare und belebende Darstellung der gemeinsamen inneren Erfahrung und, was als Lehre erscheint, ist hierzu nur Vorbereitung und Mittel." (An Lücke, S. s88.) Die kirchlicheVerkündigung und Theologie soll ihre Frömmigkeit befestigen mit Hilfe des alten logos anapodeiktos. Dieser platonische Begriff soll festhalten, da $B$ es sich um eine Darstellung handelt, die nicht in philosophisch-metaphysischer Deduktion bewiesen werden kann und auch nicht bewiesen werden soll. (An Lücke, S. 590 .)

„Niemals werde ich mich dazu bekennen können, daß mein Glaube an Christum von der Philosophie her sei." (An Lücke, S. 616.) Seine Grundintention kennzeichnet Schleiermacher folgendermaßen: "Ich hätte gewünscht, es so einzurichten, daß dem Leser möglichst auf jedem Punkt hätte deutlich werden müssen, daß der Spruch Johannes $\mathrm{I}$, Vers $\mathrm{I}_{4}$ (Das Wort ward Fleisch und wohnte unter uns, und wir sahen seine Herrlichkeit) der Grundtext der ganzen Dogmatik ist." Der Heidelberger Katechismus, der vom christlichen Grundgefühl ausgeht, hat ihn festgehalten ,in den Banden seiner rs. Frage: Was müssen wir für einen Mittler und Erlöser suchen?“

Daneben tritt dann ein zweites Anliegen, das sich schon in seiner Enzyklopädie ankündigt und das er dann in seinem Briefe an Jacobi sehr deutlich ausspricht. Ursprünglich wollte er ja seine geplante Glaubenslehre seinem verehrten Freunde Jacobi widmen, ein Vorhaben, das nur durch den Tod von Jacobi verhindert wurde (Brief an Niebuhr vom 28. März 18 I g). Schleiermacher will nicht mit dem Verstande ein Heide und mit dem Gefühl ein Christ sein. Philosophie und Dogmatik sind zwei Brennpunkte einer Ellipse. „Meine Philosophie und meine Dogmatik sind entschlossen, sich nicht zu widersprechen." Damit ist folgendes gemeint: r. Der christliche Glaube soll durch den 
Rückgang auf die Tatsache der christlichen Glaubenserfahrung der göttlichen Offenbarung sich selber von allem befreien, was er nicht selber tragen kann. Die Lehre ist nur Ausdruck für die innere Erfahrung. Daher muß man sich trennen von verbrauchten traditionellen Formeln, die eigentlich nicht Darstellung des christlichen Glaubens, sondern überholte Metaphysik sind. 2. Andererseits geht das Wissen seinen eigenen Weg und läßt sich nicht dem Glauben unterordnen. Es darf aber auf der anderen Seite auch den Glauben nicht meistern wollen und den Ursprung und den Grund der Glaubenserfahrung in der göttlichen Offenbarung durch metaphysische Deduktion ersetzen wollen. 3. Daraus ergibt sich eine Konsonanz von Glauben und Wissen, von der Schleiermacher zutiefst überzeugt ist, wenn er einen Vertrag stiften will zwischen dem auf der Offenbarung beruhenden Glauben und der freien unabhängigen wissenschaftlichen Forschung. Deutliches Beispiel für dieses Vorhaben Schleiermachers ist seine Gotteslehre im ersten Teil seiner Dogmatik. Es handelt sich hier um die Auseinandersetzung mit der supranaturalistischen Gottesvorstellung und zugleich um die Uberwindung des Gegensatzes von Supranaturalismus und naturalistischem Pantheismus. Die supranaturalistische Metaphysik sei nicht mehr als symbolischer Ausdruck für das Gottesbewußtsein tragbar. Die kritische Philosophie und ihre Zerstörung der scholastischen Metaphysik weise dem Supranaturalismus nach, da $B$ er in unerträglicher Weise endliche, welthafte Kategorien auf Gott anwende. So statuiere der Supranaturalismus über dem irdischen Raum eine zweite Dimension, ein $z$ weites Stockwerk der Himmelsphäre, das aber tatsächlich mit Kategorien der endlich irdischen Raumanschauung gedacht sei. Ebenso verfahre der Supranaturalismus bei dem Verhältnis von Ewigkeit und Zeit. Die Ewigkeit Gottes werde vor den Anfang und binter das Ende der irdischen Zeit gesetzt und damit ebenfalls auf welthafte Weise der irdischen Zeitanschauung vorgestellt. Beim supranaturalistischen Wunderbegriff gerate die Urkausalität des Schöpfers in unzulässiger Weise in Konkurrenz mit dem natürlichen Kausalzusammenhang. Es kommt Schleiermacher hierbei darauf an, Gottes Schöpfertätigkeit als Grund und Grenze der Welt so vorzustellen, daß die Abhängigkeit des Geschöpfes vom Schöpfer als schlechthinnige Abhängigkeit auch die Einordnung in den Kausalzusammenhang der Natur mit umgreift. Die Allmacht Gottes bewährt sich gerade als Voraussetzung und Grenze dieses Naturzusammenhanges, ohne daß die Abhängig- 
keit von Gott ebenso gedacht werden kann wie die Abhängigkeit. von dem Naturzusammenhang der Welt. Gott und Welt stehen für Schleiermacher daher in Korrelation, sind aber niemals identisch, und die schlechthinnige Abhängigkeit des religiösen Gefühls bezieht sich niemals auf die Welt, sondern ausschließlich auf Gott, als Grund und Grenze der Welt.

Schleiermacher selbst bezeichnet sich im Sendschreiben an Lücke als „reellen Supernaturalisten", womit er zum Ausdruck bringen will, daß er den Gegensatz zwischen Supranaturalismus und naturalistischem Pantheismus überwinden will.

Es ist Schleiermacher nicht vollständig gelungen, den pantheistischen Schein seiner Gotteslehre zu vermeiden, und er hat AnlaB zu vielen Mißverständnissen gegeben. (Glaubenslehre, I. Aufl., $\$$ Is; Abs. 5; 2. Aufl., $\$ 8$ Zus. 2). Er hat bestritten, pantheistischer Spinoza-Ausleger zu sein (Br. IV, 373). Auf der anderen Seite aber hat er den Schöpfungsglauben von den Anthropomorphismen der überlieferten scholastischen Metaphysik mit den Mitteln der kritischidealistischen Philosophie befreit und wirklich damit ernst gemacht, daß Gott niemals gegenständlich mit welthaften Kategorien gedacht werden kann, sondern nur als Urgrund und Grenze dieser Welt, weil sonst die Majestāt der göttlichen Allmacht nicht richtig verehrt wird. Viele seiner Kritiker haben gerade diesen Teil seiner Gotteslehre nicht verstanden und immer wieder versucht, auch mit Hilfe der Ewigkeit-Zeit-Dialektik in verschleierter Weise den überlieferten Supranaturalismus zu restaurieren. Dieses geistesgeschichtliche Verständnis und diese Anerkennung seiner Denkleistung in der Gotteslehre ist unabhängig von der Frage gültig, ob wir heute diese Konsonanz von Glaube und moderner Wissenschaft in naiver Weise und in primitiver Verwendung der Vertragsidee Schleiermachers nachvollziehen können, nachdem das wissenschaftliche Weltbild der idealistischen Philosophie zerbrochen ist.

Schleiermacher hat den doppelten Ansatz seiner theologischen Fragestellung und seine Theorie von den zwei Mittelpunkten einer Ellipse auch im Aufbau seiner Dogmatik zum Ausdruck gebracht. Das Schwergewicht und den Hauptakzent legt Schleiermacher auf den zweiten Teil seiner Dogmatik, der auch im Umfange der größte ist. (1 10 Paragraphen von 172 Paragraphen des Gesamtwerkes.) Er hat immer wieder erwogen, ob er diesen zweiten Teil innerhalb des Gesamtaufbaues nicht voranstellen solle, um gegenüber allen Miß- 
verständnissen seiner Kritiker diese Akzentuierung auch klar herauszustellen. In diesem zweiten Teil will er damit ernst machen, daß der Grundtext der Dogmatik Johannes 1, 14. ist. Er will das Programm entfalten, das er im $\int 11$ seiner Einleitung aufstellt und das wohl in seiner klassisch schlichten Formulierung einer der wirksamsten theologischen Lehrsätze Schleiermachers geworden ist.

„Das Christentum ist eine der teleologischen Richtung der Frömmigkeit angehörige monotheistische Glaubensweise und unterscheidet sich von anderen solchen wesentlich dadurch, $\mathrm{daB}$ alles in derselben bezogen wird auf die durch Jesum von Nazareth vollbrachte Erlösung.“ Die Darstellung des christlichen „Gottesbewußtseins" in diesem zweiten Hauptteil erfolgt in zwei Unterabschnitten. 1. In der Bestimmung durch die Sünde und 2. in der Bestimmung durch die Gnade Gottes in Christus.

Alle theologischen Aussagen über die christliche Glaubenserfahrung können in dreifacher Gestalt erfolgen:

I. als Beschreibung des christlich-frommen Selbstbewußtseins des Menseben,

2. als Begreifen der gottlichen Eigenschaften und Handlungsweisen,

3. als Aussagen über die Beschaffenheit der Welt.

Deshalb behandelt dieser zweite Hauptteil der Dogmatik im ersten Unterabschnitt erstens das Bewußtsein der Sünde als Zustand des Menschen, zweitens die Beschaffenheit der $W$ elt in Beziehung auf die Sünde, drittens die göttlichen Eigenschaften, welche dieses Bewußtsein der Sünde betreffen (die göttliche Heiligkeit und Gerechtigkeit), im zweiten Unterabschnitt: die christliche Glaubenserfahrung von der Gnade Gottes in Christus (also die Lehre von Christi Person und Werk, von der Wiedergeburt und der Heiligung); ferner das Erlösungsgeschehen in seiner Richtung auf die Welt (also die Lehre von der Entstehung der Kirche, dem Bestehen der Kirche mit der Welt und der Vollendung der Kirche), endlich die göttlichen Eigenschaften, die sich auf die Erlösung beziehen (die göttliche Liebe und Weisheit). Man kann etwas summarisch behaupten, daß Schleiermacher also in diesem zweiten Hauptteil seiner Dogmatik, den er für die eigentliche Dogmatik hält, den Gehalt des zweiten und dritten Glaubensartikels zur theologischen Darstellung gebracht hat. 
Nach s.inen eigenen Aussagen hat er diesen Hauptteil doch nicht. an den Anfang gestellt, weil er, rein formal gesehen, eine sogenannte Antiklimax nicht wünschte, er wollte nicht in seinex Dogmatik vom Wichtigeren zum Unwichtigeren hinabsteigen. Der eigentliche Grund war aber die Durchführung des von ihm beabsichtigten Vertrages zwischen Glauben und Wissen. Er will den christlichen Glauben nicht vor dem Welterkennen verteidigen, erst recht nicht mit philosophischen Mitteln begründen. Aber er will die Glaubensaussagen des ersten Artikels so zum Ausdruck bringen, daß sie von dem modernen Welterkennen aus nicht angefochten und infolge der Beimischung mit supranaturalistischer Metaphysik in Frage gestellt werden können. Der Christ steht nicht nur innerhalb der Kirche und in der Lebensgemeinschaft mit Christus, sondern gerade als Christ, solange er auf dieser Welt lebt, im Zusammenhang von Natur und Geschichte. Schleiermacher lebt in der festen Gewißheit, daß diese Welt die Welt Gottes ist und daß die Sünde des Menschen die Abhängigkeit der Welt von Gott nicht aufheben könne. Daher kam es ihm darauf an, die Glaubensaussagen des ersten Artikels möglichst rein als religiöse, als auf Gott bezogene Aussagen zu beschreiben. Das erfolgt wiederum in drei Teilen. Er untersucht das fromme Selbstbewußtsein des Menschen, ohne Rücksicht auf den Gegensatz von Sünde und Gnade: I. Sofern damit eine Aussage über das Verhältnis der Welt zu Gott gemacht ist (also die Schöpfung und Erhaltung der Welt durch Gott).

2. Die göttlicben Eigenschaften im Hinblick auf diese Abhängigkeit der Welt von Gott (Ewigkeit, Allgegenwart, Allmacht, Allwissenheit). Endlich die durch das Verhältnis von Gott und Welt bestimmten Eigenschaften der Welt (Vollkommenheit der Welt und des Menschen, d. h. die vom Schöpfer gewollte Wesensbestimmung der Welt und des Menschen).

Bei diesem sehr kunstrollen Bau einer zusammenhängenden Darstellung der christlichen Glaubenslehre geht es weniger um das kunstvolle, logische System, sondern mehr um das Aufspüren des inneren sachlichen Zusammenhanges der christlichen Glaubensaussagen und das Verstehen der einzelnen Glaubensaussage aus dem Gesamtzusammenhang heraus. Er gibt seinem System einen Vorbau durch die einleitenden Paragraphen, in denen er seine theologischwissenschaftlichen Voraussetzungen bekanntgibt. Es handelt sich um Lehnsätze aus der Ethik (d. h. Kulturphilosophie), aus der 
Religionsphilosophie (gemeint ist eigentlich eine kritisch vergleichende Religionsphänomenologie) und aus der sogenannten Apologetik (gemeint ist nicht die übliche Verteidigung des Christentums, sondern das Auffinden des eigentümlichen Wesens des Christentums) und seine methodisch-theologische Grundkonzeption. Diese Methode hat die Theologie des 19. Jahrhunderts als Methode der christlichen Glaubenserfahrung sehr stark beeinflußt bis hin zu den konfessionellen Lutheranern. Sie beruht auf einer neuen Gestaltung des reformatorischen Glaubensverständnisses und einer neuen und schärferen Analyse des Verhältnisses von Glaube und Dogma. Der reformatorische Glaube ist nicht das Annehmen von überlieferten und autoritären Lehren. Er ist daher nicht die Anstrengung, sich etwas Wesens- und Sinnfremdes, und sei es auch das Absurde, anzueignen. Die Offenbarung trifft den Menschen nicht nur in Teilen seines Lebens, sondern in der Tiefe seiner Existenz und schafft in ihm ein neues eigenes Leben. Die Offenbarung Gottes und das in der Glaubenserfahrung gesetzte "Existentialverhältnis" zu Gott (dieser Ausdruck stammt bereits von Schleiermacher [an Lücke, S. 586]) ist das Primäre. Die Lehre ist das Sekundäre, der Ausdruck der neuen Lebendigkeit des Glaubens. Bekenntnis ist Glaubensausdruck und nicht Glaubensvorschrift.

Man wird dieser methodischen Grundkonzeption Schleiermachers nicht gerecht, wenn man sie als Psychologismus und Subjektivismus verdächtigt. Gefühl als Bestimmtheit des unmittelbaren Selbstbewußtseins ist nicht die dritte psychologische Funktion neben Erkennen und Wollen, sondern der Urakt des Geistes vor der Differenzierung des Geistes in Denken, Fühlen und Wollen, besonders aber ein Vorgang des SelbstbewuBtseins, der die Spaltung in Subjekt und Objekt, wie sie das gegenständliche Erkennen vollzieht, nicht anerkennt, und die Einheit der menschlichen Existenz als Voraussetzung aller geistigen Tätigkeit begründet. Gott ist daher nicht Objekt oder Gegenstand einer erkenntnismäßigen oder ästhetischen Betrachtung. Er ist erst recht nicht eine Idee, die das Subjekt produziert. In der Bestimmtheit des Selbstbewußtseins ist Gott als das "Woher" der schlechthinnigen Abhängigkeit mitgesetzt, formuliert Schleiermacher. Abhängigkeit ist nicht ästhetische, naturhafte $\mathrm{Ab}$ hängigkeit, sondern auf dem Boden des Christentums ist die $A b-$ hängigkeit eine Glaubenshaltung, die die sittliche Frage nach dem „Wohin" der Abhängigkeit mit einschließt. Gefühl der 
schlechthinnigen Abhängigkeit ist also das Betroffensein durch das Transzendente als Unendliches und Unbedingtes. Wollte man für den gegenwärtigen Sprachgebrauch den Begriff Gefühl und unmittelbares Selbstbewußtsein so interpretieren, daß das psychologistische Mißverständnis ausgeschlossen ist, so könnte man mit der modernen Existenzphilosophie diesen Urakt menschlicher Existenz etwa kennzeichnen als Sorge um das Sein, um die Grundlegung und Sinnhaftigkeit des Daseins, wie das bereits Tillich in seiner Dogmatik anregt. Theologie der Glaubenserfahrung ist also die Beziehung aller theologischen Aussagen auf diese Grundfrage menschlicher Existenz. An diesem Punkte ist der Gegensatz Schleiermachers zur Hegelschen Spekulation wiederum ganz besonders deutlich. Es ist unmöglich, in dieser Einleitung kritisch prüfend zu berichten, welche Konsequenzen die Methode Schleiermachers für die einzelnen Lehrstücke der überlieferten Dogmatik und welche Reduktion der bisherigen ,Loci' mit ihr verbunden ist.

Der methodische Ansatz Schleiermachers ist aber nicht vollständig beschrieben, wenn nicht auch seine Schwäche und die Unzulänglichkeit seiner Darstellung erkannt wird. Schleiermacher will die Lehre von den Inhalten des christlichen Glaubens aus dem frommen Selbstbewußtsein ableiten. Seine Schüler und Nachfolger haben seine Gedanken simplifiziert und die Frage gestellt: Was muB sein, wenn die innere Tatsache des frommen Selbstbewußtseins gilt? Diese Fragestellung hat sich als unzulänglich erwiesen. Die christlich fromme Glaubenserfahrung ist nicht die Quelle der theologischen Wahrheit. Die christlich frommen Gemütszustände sind nicht identisch mit der Offenbarung, die christliche Glaubenserfahrung ist das Medium der Offenbarung, aber nicht die Offenbarung selbst. Die Antithese gegen die scholastisch-theologische Denkweise hat Schleiermacher dazu verführt, daß er diesen Sachverhalt nicht klar genug hervorgehoben hat. Mit dieser Einschränkung und Korrektur darf man aber vielleicht behaupten: Schleiermachers theologische Denkmethode und seine Zerstörung der scholastischen Denkweise ist die Anwendung der Lehren des dritten Artikels vom Hl. Geist auf die Prinzipien des theologischen Denkens, eine Anerkennung, die selbst Karl Barth, wenn auch mit gewissen Einschränkungen dem Verfasser der Glaubenslehre zugesteht. (Dogmatik im Grundriß 1947 S. 160f.) 


\section{DIE WURDIGUNG UND KRITTK}

\section{DER GLAUBENSLEHRE IM NEUPROTESTANTISMUS}

Die Freunde Schleiermachers zollten seiner Glaubenslehre höchstes Lob und Anerkennung. Sie prophezeiten, $\mathrm{daB}$ mit ihr eine neue Epoche des theologischen Denkens beginnen werde. „Was ich aber neben jenem Bericht Dir, mein teurer Freund, allein sagen muß, ist, $\mathrm{daB}$ ich nie an einer Schrift, auch noch an keiner von Dir, eine so reine Freude gefunden habe als an dieser und ich will auch hinzusetzen, mich noch nie so glücklich gefühlt habe, ein Christ und ein Geistlicher zu sein, als bei dieser Darstellung ... Das aber soll mir auch niemand abstreiten, da $B$ mit Deiner Dogmatik eine neue Epoche nicht nur in dieser Disziplin, sondern im ganzen theologischen Studium beginnen wird, und wenn dies auch nicht plötzlich und auf einmal, so wird es doch künftig geschehen" (Briefwechsel mit Gaß, S. 95). Man verglich die wissenschaftliche Leistung der Glaubenslehre mit Calvins Institutio. Karl von Hase urteilt in seiner Kirchengeschichte, "diese Dogmatik enthielt die Umbildung und Vermittlung der Religion seiner Reden mit der kirchlichen Theologie. Für das Universum tritt hier der Name Gottes ein, für die Erlösung als Tat des Selbstbewußtseins der Erlöser. An wissenschaftlicher Schärfe und christlicher Tiefe ist mit dieser Glaubenslehre nur Calvins Dogmatik zu vergleichen“ (III/2 S. 386). „Nicht durch eine besondere Lehre wird das Christentum fortgepflanzt, sondern durch die Lebensgemeinsrhaft mit dem Herrn. Insofern kommt alles Heil durch ihn. Hier scheidet sich der frühere und der spätere Schleiermacher als Religionslehrer, und man könnte den Unterschied seiner Glaubenslehre und seiner Reden sich wohl durch ein Gleichnis anschaulich machen: Schleiermacher, wie er auf den Wogen des Universums, gleichsam des Weltmeers, dahintreibt, exblickt und exgreift, ein zweiter Petrus, die rettende Hand des Heilands" (S. 387). In der Real-Enzyklopädie für die protestantische Theologie und Kirche, 13. Band, Seite 543 bekennt der jüngere Gaß: „Es ist ein Denkmal religiöser Begeisterung und wissenschaftlicher Denkkraft zugleich, 
gediegener und in sich vollendeter als alle früheren Jeistungen des Verfassers, ein systematisches Kunstwerk, welches in der theologischen Litteratur dieses Jahrhunderts seinesgleichen nicht hat, und mit dem aus der älteren etwa nur Calvins Institutio verglichen werden kann."

In der Verurteilung seiner Glaubcnslehre dagegen vereinigten sich völlig heterogene Richtungen. Die alten Supranaturalisten und ihre neuorthodoxen Nachfolger, die im 19. Jahrhundert ein merkwürdiges Bündnis mit dem Pietismus eingegangen waren, verdammten ihn. Die schärfste Sprache führte die von Hengstenberg redigierte evangelische Kirchenzeitung. Schon 1829 bezeichnete sie den frommen Gemütszustand, von dem aus Schleiermacher seine Glaubenslehre entwickle, als „Unglauben im Glaubenwollen“. 1830 hieß es, die von Schleiermacher geforderte evangelische Freiheit sei lediglich Freiheit vom Evangelium. Er sei nicht der Uberwinder des Rationalismus und der Begründer eines neuen Glaubens. Er vermische Pantheismus und Christentum. Seine Dogmatik sei ein theologischer Schwindel. Tholuck behauptete, Schleiermacher habe die Gabe, alles beweisen zu können, was er wolle. Auch nach seinem Tode verfolgte man ihn mit bissiger Polemik. Wer an dem Geburtstage Schleiermachers gedenke, verstoße gegen das Verbot von 2. Kor. 6 Vers 14 (,ziehet nicht am fremden Joch mit den Ungläubigen, denn was hat die Gerechtigkeit zu schaffen mit der Ungerechtigkeit? Was hat das Licht für Gemeinschaft mit der Finsternis ?") Einen ähnlichen peinlichen Ton schlug auch die rationalistische Predigerbibliothek von Röhr an. Schleiermachers Religion sei ohne Moral, seine Theologie sei Täuschung. In diesen Zusammenhang gehört auch das boshafte Spottgedicht von A. W. Schlegel' :

Der nackten Wahrheit Schleier machen ist kluger Theologen Amt und Schleiermacher sind bei so bewandten Sachen die Meister der Dogmatik insgesamt.'

Außer den orthodoxen Rationalisten tadelten ihn auch die Hegelianer nach dem Vorgang ihres Meisters. F. Chr. Baur ${ }^{2}$ und David

1 A. W. Schlegel: Sämtl. Werke (Ed. Böcking) 2. Bd. S. 233 Leipzig 1846.

2 F.Chr. Bauer: Primae rationalismi et supranaturalismi historiae ... Tübingen 1827 .

Die christliche Lehre von der Versöhnung Tübingen 1838 S. 614 ff. 
Friedrich Strauß ${ }^{1}$ wiederholten den Vorwurf der Täuschung. Er gebe sich nur den Schein der Kirchlichkeit und der Orthodoxie, zerstöre aber in Wirklichkeit den christlichen Glauben. Strauß verglich den kunstvollen Bau der Glaubenslehre mit einem modernen, elegant eingerichteten Pavillon, in den alle Leute einzogen, abgesehen von ein paar alten Hauskatzen. Dennoch enthalte das veraltete Rattennest der alten Dogmatik schr viel mehr Wert an Steinen und Eisenwerk, als das neue unsolide gebaute Gartenhäuschen. Bei der Verurteilung Schleiermachers wurden hauptsächlich sein Religionsbegriff, seine Gotteslehre und seine Christologie angegriffen. Rationalisten und Hegelianer hatten gar kein Verständnis dafür, $\mathrm{da} B$ die Religion eine Bestimmtheit des Gefühls oder des unmittelbaren Selbstbewußtseins sein soll.

Für Hegel2 und seine Schüler war das Gefühl etwas Untergeistiges, ja Unbewußtes, instinkthaft Untermenschliches. Von da aus ist die eines Philosophen vom Range Hegels nicht gerade würdige Polemik in der Einleitung zur Hinrichschen ${ }^{3}$ Religionsphilosophie abzuleiten. „Ist das Gefühl der schlechthinnigen Abhängigkeit das Wesen der Religion und des christlichen Glaubens", so wäre nach Hegel „der Hund der beste Christ, denn er trägt dieses am stärksten in sich und lebt vornehmlich in diesem Gefühle. Auch Erlösungsgefühle hat der Hund, wenn seinem Hunger durch einen Knochen Befriedigung wird. Nur der freie Geist hat Religion und kann Religion haben". Gewiß solle die Religion, wie Pflicht und Recht, auch Sache des Gefühls werden, aber nicht aus dem Gefühle geschöpft sein, sondern ihr objektiver Gehalt solle an und für sich gelten. Schleiermacher überging diese boshafte und unsachliche Kritik mit Stillschweigen.

Seine Gotteslehre wurde von den verschiedenen Seiten als Pantheismus verdächtigt. Als typisches Beispiel sei die Schrift von Delbrück ${ }^{4}$, der Schleiermacher sehr energisch entgegentrat (Br. IV, 373) und David Fr. Strauß genannt. Letzterer behauptete, man könne alle Glaubenssätze des ersten Teils der Glaubenslehre in die lateinischen Formulierungen Spinozas zurückübersetzen. Anlaß zu dieser bos-

1 D. Fr. Strauß: Die christliche Glaubenslehre Tübingen 1841 S. 175 ff.

2 "Das Widermenschliche, das Tierische besteht darin, im Gefühl stehen zu bleiben".

Hegel: Vorrede zur Phänomenologie. Ausg. Glockner Bd. II S. 63.

3 Hinrichs: Die Religion in ihrem Verhältnis zur Wissenschaft Heidelberg 1822.

' F. Delbrück: Erörterung einiger Hauptstücke usw. Bonn 1827. (vgl. u. S. 23) 
haften Ubertreibung war der Sachverhalt, $\mathrm{da} B$ sich in der Glaubenslehre (2. Aufl., $\$ \$ 4$ u. \$9) in der Tat bei gewissen Formulierungen Anklänge an Spinozas Gotteslehre finden, die aber im Gesamtzusammenhang dex Gedankenführung Schleiermachers ihren pantheistischen Sinn verlieren und sich als umdeutendes Mißverstehen Spinozas durch Schleiermacher erweisen. Die Hegelianer Baur und Strauß bekämpften die Christologie Schleiermachers. Sie erkannten, daß die Christologie Schleiermachers nicht nur ein Einschub, sondern die Grundlage seines Systems sei und wollten mit der Christologie Schleiermachers sein gesamtes dogmatisches System ad absurdum führen. Beide Hegelianer wollten Schleiermacher verbieten, daß er Urbildlichkeit und Geschichtlichkeit Christi miteinander verbinde, weil die Urbildlichkeit des unsündlichen vollkommenen Gottesbewußtseins Jesu, da sie als Idee im Hegelschen Sinne zu werten sei, nicht in einem einzelnen geschichtlichen Individuum sich vollkommen verwirklichen könne. Baur ordnete daher Schleiermacher unter die gnostischen Ketzer ein. In Wirklichkeit sei die Schleiermachersche Christus-Urbildlichkeit ungeschichtlich. Sie sei nur die Idee der Humanität in einem einzelnen Individuum angeschaut, aber doch eben eine Idee, die nur als Ziel für die unendliche Entwicklung der Menschheit gedacht werden könne.

Diese kritischen Einwände seiner Zeitgenossen, besonders aber die der Generation unmittelbar nach ihm, die durch den Zusammenbruch der idealistischen Wissenschaftslehre und Lebensanschauung geprägt war, wurden dann in der zweiten Hälfte des ig. Jahrhunderts von $A$. Ritschl und einem Teil seiner Freunde wiederholt. Ritschl urteilte, daB die Christologie Schleiermachers ungeschichtlich sei, weil sie die Lehre von Person und Werk Christi aus der Tatsache der inneren Glaubenserfahrung und nicht von dem geschichtlichen Jesus ableite. Sie kritisierten seinen Subjektivismus, der nicht die Offenbarung Gottes zur Geltung kommen lasse und nicht das rechte Verhältnis zur Heiligen Schrift habe. Besonders hatten aber Ritschl und seine Schüler gar kein Verhältnis zur Theologie der Schöpfung, die Schleiermacher im ersten Teil seiner Glaubenslehre geboten hatte. An die Stelle der Ontologie Schleiermachers war die neukantische Erkenntnistheorie und Ethik getreten. Daher verkannten sie die wissenschaftliche Begrifflichkeit Schleiermachers. Infolge ihrer engen Verbindung mit der kantischen Ethik glaubten sie, im Schleiermacherschen Religionsbegriff lediglich eine ästhetische 
Mystik zu finden, die nicht mit der sittlichen Erlösungsteligion des Christentums zu vereinbaren sei.

Diese bereits von den Ritschlianern erhobenen Einwände erfuhren eine radikale Steigerung in der Frühperiode der dialektischen Theologie. Schleiermacher steht seitdem unter dem Verdikt, daß er die protestantische Dogmatik mit der Philosophie des deutschen Idealismus verflochten habe und damit die als verhängnisvoll angesehene Entwicklung der sogenannten neuprotestantischen Theologie, die mit der Aufklärung und dem Pietismus einsetzte, durch die Schärfe seines Geistes und seine dialektische Auslegungskunst erst recht zur verhängnisvollen Auswirkung gebracht habe. Der durch Schleiermacher geschlossene Bund zwischen Theologie und idealistischer Philosophie, die damit erfolgte Vermischung von christlichem Glauben und menschlichem Streben nach Selbsterlösung und Selbstrechtfertigung in Bildung und Kultur habe die protestantische Theologie überhaupt erst in das Verderben des Subjektivismus, Relativismus, Psychologismus, Historismus und Anthropozentrismus hineingeführt. Diese Verflochtenheit der Theologie mit der idealistischen Philosophie, mit der modernen Kultur- und Bildungsgläubigkeit sei nunmehr zu lösen, und es sei vielleicht am besten, diese Periode des Neuprotestantismus nicht mehr als bedeutsames geschichtliches Erbe anzusehen, sondern sich andere Väter und Vorbilder für Kirche und Theologie aus der Zeit der Reformation und der Alten Kirche zu wählen.

Theologie sollte nicht mehr zum Gegenstand das menschliche Religionsbewußtsein, seine Entwicklung, seine psychologischen und soziologischen Wandlungen und Bedingtheiten haben, sondern sollte ausschließlich und konsequent Lehre von Gott auf Grund seiner Selbstoffenbarung in Christus sein. Gerade dieses zentrale Anliegen sei durch das geistreiche Feuerwerk der Schleiermacherschen Dialektik, Psychologie und Kulturphilosophie verdeckt und verschleiert worden.

Für die gegenwärtige dialektische Theologie, die sich zu einer konsequent logozentrischen oder kerygmatischen Theologie entwickelt hat, ist das Wort Gottes, die Heilsbotschaft von Christus, in erster Linie Beunruhigung und Erschütterung. „Es ist sinnlos, eine Religion aus ihr (der Heilsbotschaft von Christus) zu machen, das hieße eine menschliche Möglichkeit und Notwendigkeit, neben der es andere gibt." „Dieser Versuch, bewußter als je zuvor unternom- 


\section{XXXVIII}

men in der protestantischen Theologie seit Schleiermacher, ist der Verrat an Christus" (Karl Barth, Römerbricf, 8. Aufl. S. 207).

Diese Polemik gegen Schlejermacher stützt sich meist weniger auf eine genaue Einzelauseinandersetzung mit den Gedankengängen der Glaubenslehre. Schleiermacher wurde zum Prototyp der verderblichen neuprotestantischen Kulturtheologie, welche die biblische Botschaft von Gottes Gottheit und das Ärgernis des Kreuzes verwandelte in eine menschliche Selbstbetrachtung subjektiver religiöser Erlebnisse und darum der Feuerbachschen Illusionstheorie nicht standhalten könne. Diese grundsätzliche Ablehnung liegt der Interpretation der Glaubenslehre Schleiermachers in dem bekannten Buche von Emil Brunner ${ }^{1}$ zugrunde. Die Kritik ist so einseitig und der Sachverhalt ist so simplifiziert, daß Karl Barth² korrigierend in die Diskussion über Schleiermacher eingriff. Brunner versucht nachzuweisen, daß der Religionsbegriff Schleiermachers in seiner Glaubenslehre ein kunstvolles Ineinandergehen von Mystik und Identitätsphilosophie sei. Schleiermachers Aussagen über das fromme Selbstbewußtsein verfehlten den Objektgehalt des Glaubens und seien lediglich eine Selbstbetrachtung der inneren Zustände des Subjekts. Agnostischer Expressionismus trete an die Stelle des Kerygmas. Das Wort von Jesus Christus sei ein störender Einschub, der nicht zu der Gesamtkonzeption passe. Der Selbstgenuß des Mystikers führe zur Verkennung des Ethos und zu psychologistischer Immanenzphilosophie. Schleiermachers Glaubenslehre biete eine naturalistische evolutionistische Umdeutung der biblischen Sündenlehre und eine Relativierung des Abstandes zwischen dem heiligen Gott und der Sünde. Der Entwicklungsoptimismus und das Vertrauen auf die innere Unendlichkeit der Welt eliminiere die Eschatologie. So werde die Störung, die die Immanenzphilosophie und Mystik durch die Christologie erfahre, abgewehrt. Selbstverständlich erfolgt auch der Vorwurf des Pantheismus; als Beweis wird Schleiermachers Kritik an der supranaturalistischen und persönlichen Gottesvorstellung herangezogen.

Die Schleiermacherkritik der Ritschlianer und der dialektischen Theologie in ihrer Frühperiode verfehlte ihr Ziel, weil sie durch die Vorurteile der neukantischen Erkenntnistheorie und Lebensanschauung und durch die philosophischen und theologischen Vorausset-

1 E. Brunner: Die Mystik und das Wort 2. A. Tübingen 1928.

- K. Barth: „Zwischen den Zeiten" 1924 H. 8 u. 1927 S. 422 f. 
zungen der kulturkritischen Theologie bedingt war. Dadurch entstand ein sehr einseitiges, ja man darf sagen, verstelltes Bild der Gedankenwelt Schleiermachers. Inzwischen hat sich die geistige Situation gewandelt. Die Vorurteile des Neukantianismus und der radikalen theologischen Kulturkritik sind aufgelockert worden. So ist der Weg zu cinem neuen geistesgeschichtlichen Verstehen Schleiermachers frei geworden. Wir können nicht naiv zu den Konzeptionen Schleiermachers zurückkehren, besonders deswegen, weil der Hauptgesprächspartner Schleiermachers in seiner theologischen Denkarbeit: die idealistische Lebensanschauung und Wissenschaftslehre nicht mehr dic unsrige ist. Um Schleiermacher aber richtig würdigen zu können, muß man ihn aus den geistigen Voraussetzungen seiner Zeit begreifen; vielleicht wird man dann auch entdecken, wie weit er bereits ü'Jer die Schranken der idealistischen Jebensanschauung und Wissenschaftslehre hinausgeschaut hat. Zweifellos ist auch unser hcutiges Verständnis durch bestimmte philosophische und theologische Voraussetzungen bestimmt. Aber vermutlich können wir von unseren anderen und neuen Ausgangspunkten Motive und Impulse seiner Gedankenbildung entdecken, die der Kritik der jüngsten Vergangenheit verborgen blieben. Man kann auch nicht einfach die Periode der neuprotestantischen Dogmatik, die Schleiermacher maßgeblich beeinflußte, durch ein nachträgliches Verdikt aus der Geschichte der protestantischen Theologie streichen. Es gilt auch heute noch das Wort Rankes, daß jeder Theologe erst durch die Auseinandersetzung mit Schleiermacher zur rechten Freiheit gelangen könne. Einer solchen neuen geschichtlichen Würdigung Schleiermachers hat bereits Karl Barth in seiner Geschichte der protestantischen Theologie zugestimmt und einen beachtlichen Beitrag zu ihr geliefert. Er meint, daß Schleiermacher auf die Fragen seiner Zeit eine Antwort erteilt habe, die den Besten seiner Zeit genügt habe, er habe also den Auftrag der Theologie in seiner Zeit effolgreich aufgegriffen und durchgeführt.

Es geht dabei um mehr als um eine theologiegeschichtliche Würdigung Schleiermachers. Die Probleme der neuprotestantischen Theologie sind nicht einfach gewaltsam zu beseitigen. Die Debatte über die Entmythologisierung hat bereits gezeigt, daB die Grundkonzeption der Christologie Schleiermachers zu erneuter Prüfung und Läuterung ihres Ansatzes uns auffordert, wie das bereits Paul Tillich in seiner systematischen Theologie deutlich gemacht hat. Die 
XL

ontologische Fragestellung, die spezielle Gotteslchre und dic Uberwindung des Gegensatzes von Supranaturalismus und naturalistischem Pantheismus, die von uns von neuem gefordert wird, läßt auch Schleiermachers Gotteslehre in einem neuen Lichte erscheinen. Endlich hat auch die Frage der modernen Existenzphilosophie nach der Entfremdung der menschlichen Existenz und dem Wahrhaftigwerden menschlicher Existenz vor Gott zu erkennen gegeben, wie stark Schleiermacher bereits seiner Zeit, die von der metaphysischen Spekulation Hegels und Schellings beherrscht war, vorangeschritten war. Dieses Neue bei Schleiermacher ist für uns heute besonders wichtig in der Auseinandersetzung mit dem modernen Atheismus und der modernen Skepsis. So ist eine erneute Beschäftigung mit der Glaubenslehre Schleiermachers nicht nur von der theologiegeschichtlichen, sondern auch von der prinzipiell aktuellen Fragestellung der Gegenwart fruchtbar und erforderlich.

Für eine solche Untersuchung ist die Kenntnis der Quellen notwendig. Dazu möchte diese Neuausgabe der Glaubensiehre Schleiermachers einen Beitrag liefern. Möge die Glaubenslehre Schleiermachers das heutige Theologengeschlecht anregen, sich mit seiner Denkleistung auseinanderzusetzen und dabei den Gewinn davontragen, über den Friedrich Naumann auf Grund eigener Erfahrungen in seinen Kandidatenjahren berichtet. Naumann bekennt, daß ihn die Glaubenslehre durch ihr hohes Niveau aus dem Theologenstreit der damaligen Gegenwart herausgehoben habe und daß er einen Frieden Gottes gefunden habe, der höher ist als alle Vernunft, sowohl der Orthodoxie wie der Antiorthodoxie. Es ist ihm zuzustimmen, wenn er für nebensächlich hält, ob man dasselbe glaubt, was Schleiermacher geglaubt und formuliert hat. Hauptsache ist, daß man zum Lernen bereit ist und zum Umdenken, wie ex es getan hat bis an sein Ende. 


\section{ZUR EINRICHTUNG VON TEXT UND APPARAT}

Der vorliegenden Ausgabe liegt der von Schleiermacher selbst besorgte Text der 2. Auflage der Glaubenslehre (1830/31) zugrunde.

Die Seitenzahlen der Ausgabe von I $830 / 31$ sind hier am Rande angegeben.

Der I. Apparat enthālt die von C. Thönes herausgegebenen handschriftlichen Anmerkungen Schleiermachers zum I. Teil der Glaubenslehre (Berlin 1873). Durch kleine lateinische Buchstaben ist auf die entsprechenden Textstellen hingewiesen.

Im 2. Apparat finden sich die Nachweise der Zitate Schleiermachers, auf die mit kleinen griechischen Buchstaben verwiesen wird, sowie mit * bezeichnete Konjekturvorschläge und Erläuterungen.

Der Text Schleiermachers, wie er ihn in seiner 2. Auflage hinterließ, wurde in seinem Lautbestand erhalten, aber die alte Orthographie (z. B. der Gebrauch der Konsonanten "tz", „th", „kk" oder die völlig uneinheitliche Trennung der Komposita) durch die moderne Schreibweise ersetzt, wie das jetzt bei den meisten Ausgaben aus der Zeit Schleiermachers üblich geworden und sich als nützlich erwiesen hat.

Die Bewahrung des Lautbestandes dient der Erhaltung des Stils, des Klanges und des Rhythmus der Sprache Schleiermachers. Deshalb mußten zahlreiche uns heute ungewohnte Wortformen und grammatische Besonderheiten stehenbleiben (z. B. „das" Verkehr, hiebei, desohnerachtet). Auch die bei unserm Autor völlig regellose Verwendung des Vokals , ,e“, z. B. in den Worten: and(e)re, eig(e)ne, anseh(e)n des Originaltextes, ist erhalten worden.

Der heutige Leser hat manchmal Mühe, die langen ineinander verschachtelten Satzperioden Schleiermachers zu verstehen. Es handelt sich dabei nicht in erster Linie um eine Besonderheit Schleiermachers. Vielmehr findet sich dieser kunstvolle und oft schwierige Satzbau auch in Prosaschriften Goethes und anderer

Zeitgenossen. Für das Verständnis solcher Satzperioden ist die Interpunktion unter Umständen eine Hilfe. Leider ist aber die Interpunktion bei Schleiermacher ebenso wie bei Goethe ofr inkonsequent und manchmal sogar verwirrend. Daher hat der Herausgeber versucht, durch sinngemäße Zeichensetzung das Lesen des Textes zu erlcichtern. Es ist dabei zu berücksichtigen, daß eine solche Interpunktion bereits eine gewisse Interpretation bedeuten kann. Deshalb hat der Herausgeber ausgesprochene Besonderheiten der Zeichensetzung Schleiermachers, z. B. die Verwendung des Doppelpunktes zur Kennzeichnung des Hauptsatzes und des Höhepunktes einer Satzperiode beibehalten, auch wenn sie den Regeln der heutigen Interpunktion nicht entspricht. 


\section{VERZEICHNIS DER ABKURZUNGEN}

BB = Die Bekenntnisschriften der evangelisch-lutherischen Kirche. Herausgegeben vom Deutschen Evangelischen Kirchenausschuß. Göttingen r930.

CR $=$ Corpus Reformatorum.

MSG = Migne, Patrologiae Cursus Completus, Serien Graeca.

MSL = Migne, Patrologiae Cursus Completus, Series Latina.

Niem. $=$ H. A. Niemeyer, Collectio confessionum in ecclesiis reformatis publiratarum. Leinzig 1840.

Pünjer $=$ G. Ch. Bernhard Pünjer, Friedrich Schleiermachers Reden über die Religion. Kritische Ausgabe. Braunschweig 1879.

Schol $z=$ Heintich Scholz, Schleicrmachers Kurze Darstellung des Theologischen Studiums. Kritische Ausgabe. Leipzig 1910.

WA $=$ Luthers Werke. Weimarer Ausgabe.

$W W=$ Friedrich Schleiermachers sämtliche Werke. Berlin 1835 ff.

Th $=\mathrm{C}$. Thönes, Schleiermachers handschriftliche Anmexkungen zum ersten Teil der Glaubenslehre. Berlin 1873. 